\title{
Subsidiariedad y educación en Chile: estudio histórico de un principio político polisémico
}

\author{
Pablo Barnier-Khawam
}

\section{RESUMEN}

A partir de un estudio histórico e ideológico del concepto de subsidiariedad, este artículo propone un análisis de su aplicación en el ámbito de la educación en Chile. De esta manera, se demuestra el rol del jurista Jaime Guzmán en la conjugación de la tradición católica con el pensamiento neoliberal, al integrar la subsidiariedad en el sistema jurídico chileno. La ambivalencia de este principio de organización institucional permite justificar el carácter democrático del sistema educativo gracias a la libertad de enseñanza que consagra. La transición democrática profundiza este modelo con una ampliación de la oferta privada en la educación superior, lo que demuestra una continuación ideológica en cuanto al concepto de subsidiariedad. Sin embargo, este mismo concepto puede tener otro contenido ideológico partiendo de la idea que la educación debe entenderse como un ámbito social fuera de la lógica de mercado, como lo demuestran los movimientos estudiantiles en Chile. Una propuesta horizontal de la subsidiariedad puede así ser teorizada.

Palabras clave: subsidiariedad, Chile, Jaime Guzmán, neoliberalismo, libertad de enseñanza. 


\section{Subsidiariedade e educação no Chile: estudo histórico de um princípio político polissêmico}

\section{RESUMO}

A partir de um estudo histórico e ideológico do conceito de subsidiariedade, este artigo propõe uma análise de sua aplicação no âmbito da educação no Chile. Desta maneira, se demostra a função do jurista Jaime Guzmán na conjugação da tradição católica com o pensamento neoliberal, ao integrar a subsidiariedade no sistema jurídico chileno. A ambivalência deste princípio de organização institucional permite justificar o caráter democrático do sistema educativo graças à liberdade de ensino que consagra. A transição democrática aprofunda este modelo com uma ampliação da oferta privada na educação superior, o que demostra uma continuação ideológica em quanto ao conceito de subsidiariedade. Porém, este mesmo conceito pode ter outro conteúdo ideológico partindo da ideia que a educação deve ser entenda como um âmbito social fora da lógica de mercado, como demostram os movimentos estudantis no Chile. Uma proposta horizontal da subsidiariedade pode assim ser teorizada.

Palavras chave: subsidiariedade, Ghile, Jaime Guzmán, neoliberalismo, liberdade de ensino.

\section{Subsidiarity and education in Chile: historical study of a polysemic political principle}

\section{ABSTRACT}

Based on a historical and ideological study of the concept of subsidiarity, this article proposes an analysis of its application in the field of education in Chile. In this way, the role of the jurist Jaime Guzmán is shown as a synthesis of the Catholic tradition with the neoliberal thought, when integrating the subsidiarity in the Chilean juridical system. The ambivalence of this institutional organization principle allows to justify the democratic character of the educational system thanks to the freedom of teaching that it enshrines. The democratic transition deepens this model with an expansion of private provision in higher education, which demonstrates an ideological continuation of the concept of subsidiarity. However, this same concept can have another ideological content based on the idea that education should be understood as a social sphere outside the logic of the market, as demonstrated by the student movements in Chile. A horizontal proposal of subsidiarity can thus be theorized.

Key words: subsidiarity, Chile, Jaime Guzmán, neoliberalism, freedom of education. 


\section{Introducción}

"El Estado reconoce y ampara a los grupos intermedios a través de los cuales se organiza y estructura la sociedad y les garantiza la adecuada autonomía para cumplir sus propios fines específicos", dice el tercer inciso del artículo 1 de la Constitución de 1980 de la República de Chile que todavía está vigente. El inciso define el principio de subsidiariedad que rige varias acciones del Estado chileno desde el golpe de Estado de 1973. Siendo una herramienta analítica que permite pensar la noción de soberanía en la filosofía política, la subsidiariedad es utilizada en el contexto chileno según una tradición católica, conservadora y neoliberal que se sintetiza en el pensamiento de Jaime Guzmán. La aplicación de la subsidiariedad dentro del aparato estatal es paradigmática en el ámbito de la educación chilena. Por esa razón, nos encargaremos de explicar cómo se justifica e implementa ese principio demostrando así el carácter paradigmático de una cierta forma de la subsidiariedad en el caso educacional en Chile. La especificad de esa implementación puede encontrar la posibilidad de su generalización bajo el estudio del carácter fundamental que ocupaba el principio de subsidiariedad dentro del pensamiento político, económico y filosófico de la dictadura y, en particular, de su pensador más destacado, Jaime Guzmán. Sin embargo, nuestro propósito es demostrar que la subsidiariedad es ambivalente. Su interpretación e implementación por la dictadura de Augusto Pinochet es particular y sirve a la justificación de la instauración de un orden democrático dentro de la perpetuación de actos que violaron abiertamente los derechos humanos. Una tensión se destaca así de la ambigüedad que lleva consigo el concepto de subsidiariedad y su posible uso ideológico.

¿Cómo la aplicación del principio de subsidiariedad dentro del sistema educacional durante la dictadura de Pinochet sirvió para justificar una apariencia democrática del régimen autoritario?

Primero, estudiaremos la aplicación del principio de subsidiariedad en la educación durante la dictadura de la junta militar y la transición democrática y, por eso, tenemos que precisar la base ideológica de ese principio que mezcla teorías católicas y neoliberales. En un segundo tiempo, discutiremos una aplicación alternativa de la subsidiariedad y de su posible aplicación democrática al ámbito educacional.

\section{La aplicación del principio de subsidiariedad en el sistema educativo chileno de 1973 a los años noventa La subsidiariedad, un principio heredero de la tradición católica}

La palabra subsidiariedad proviene del latín "subsidium, cuyo significado original se remonta a la idea de 'dejar algo en reserva' o, más específicamente, de 'tropas de reserva'. [...] Con el paso del tiempo adquirió su sentido actual de 'ayuda, apoyo o alivio'. Así, subsidiariedad no significa suplantación, pero tampoco abstención de intervenir por parte del Estado" (Ortúzar, 2015: 5). El principio de subsidiariedad encuentra una formulación teórica ya en La Política de Aristóteles, pero su conceptualización más precisa se debe a Tomás de Aquino quién va a difundir ese principio dentro de la teología católica (ibid.). El teólogo dice que las comunidades humanas se forman dentro de "órdenes graduales" que consisten todas ellas en "partes que en alguna medida operan de manera independiente y en otra son parte de las operaciones del todo" (Aroney, 2014: 20). Reconceptualizando a Aristóteles, según el pensamiento católico, Tomás de Aquino reconoce la naturaleza social y política del ser humano y establece una jerarquía entre los diferentes cuerpos sociales; ellos mismos tienen una capacidad de autosuficiencia distinta a otros, además de distinguir esos últimos también por sus funciones.

Un Estado autoritario se caracteriza por la supresión de esa autonomía de los cuerpos sociales, es decir que trataría de buscar "disminuir todas las formas de solidaridad social entre sus súbditos, evitando que se reúnan en grupos y asociaciones entre individuos 
y familias a partir de las cuales se generan la amistad, la familiaridad y la confianza" (ibid:: 23). Un Estado respetuoso del principio de subsidiariedad, como lo define Tomás de Aquino, sería un Estado "proveedor de las condiciones externas esenciales bajo las cuales los individuos, las familias y otras organizaciones son capaces de florecer y contribuir al bien común" (Ortúzar, 2015: 6). Ortúzar teoriza una noción colectiva del bien común, al contrario de Jaime Guzmán que, conservando el aspecto perfeccionista de la definición, le da una connotación más individual ya que, según él, el bien común "debe entenderse como el conjunto de condiciones sociales que permita a cada uno de los seres humanos que lo integran alcanzar su fin personal, o sea, su perfección, en la mayor medida posible" (Guzmán, 1993: 46).

Entre el fin del siglo XIX y el principio del siglo $\mathrm{XX}$, la subsidiariedad se precisa teóricamente gracias a dos papas, Pío IX (1846-1878) y León XIII (18781903), que van a fijar una interpretación del principio según la Iglesia Católica. En la famosa encíclica Rerum Novarum. Sobre la condición de los obreros (1891), León XIII precisa la noción de subsidiariedad afirmando que: "no es justo, según hemos dicho, que ni el individuo ni la familia sean absorbidos por el Estado; lo justo es dejar a cada uno la facultad de obrar con libertad hasta donde sea posible, sin daño del bien común y sin injuria de nadie. No obstante, los que gobiernan deberán atender a la defensa de la comunidad y de sus miembros" (León XIII, 1891: 26).

En la misma encíclica, el papa subraya el hecho de que el ser humano posee una propensión natural "a buscarse el apoyo de los demás" y que esa misma propensión hace que forme "otras sociedades entre ciudadanos, pequeñas e imperfectas, es verdad, pero de todos modos sociedades. Entre éstas y la sociedad civil median grandes diferencias por causas diversas" (ibid.: 35). El papa distingue así la sociedad civil, que busca el bien común y permite la participación de todos, y las sociedades privadas que se forman dentro de la sociedad civil y cuya "finalidad inmediata es el bien privado de sus miembros exclusivamente" (ibid.). El papa define claramente el rol del Estado frente a las sociedades privadas:

no está en poder del Estado impedir su existencia, ya que el constituir sociedades privadas es derecho concedido al hombre por la ley natural, y la sociedad civil ha sido instituida para garantizar el derecho natural y no para conculcarlo; y, si prohibiera a los ciudadanos la constitución de sociedades, obraría en abierta pugna consigo misma, puesto que tanto ella como las sociedades privadas nacen del mismo principio: que los hombres son sociables por naturaleza. Pero concurren a veces circunstancias en que es justo que las leyes se opongan a asociaciones de ese tipo; por ejemplo, si se pretendiera como finalidad algo que esté en clara oposición con la honradez, con la justicia o abiertamente dañe a la salud pública (León XIII, 1891: 35).

En la encíclica de Pío XI, Quadragesimo Anno. Sobre la restauración del orden social (1931), el principio de subsidiariedad católico encuentra la versión más difundida. Ésa establece que:

como no se puede quitar a los individuos y dar a la comunidad lo que ellos pueden realizar con su propio esfuerzo e industria, así tampoco es justo, constituyendo un grave perjuicio y perturbación del recto orden, quitar a las comunidades menores e inferiores lo que ellas pueden hacer y proporcionar y dárselo a una sociedad mayor y más elevada, ya que toda acción de la sociedad, por su propia fuerza y naturaleza, debe prestar ayuda a los miembros del cuerpo social, pero no destruirlos y absorberlos (Pío XI, 1931: 79).

La encíclica da la prioridad al Estado en "todo aquello que es de su exclusiva competencia, en cuanto a que sólo él puede realizar, dirigiendo, vigilando, urgiendo y castigando, según el caso requiera y la 
necesidad exija" (ibid:: 80). La subsidiariedad encuentra así sus dos fases. La primera, negativa, niega a la autoridad pública la posibilidad de absorber las sociedades menores y establece así lo que se llama un principio de no-absorción. La segunda, positiva, otorga al Estado la competencia, según un principio de habilitación o de suplencia, las prerrogativas que las sociedades menores son incapaces de ejercer.

Esa teorización conduce a la crítica directa del Estado de bienestar como autoridad pública hipertrofiada. En la encíclica Centesimus Annus, el papa Juan Pablo II (1991: 48) explica que "el Estado asistencial provoca la pérdida de energías humanas y el aumento exagerado de los aparatos públicos, dominados por lógicas burocráticas más que por la preocupación de servir a los usuarios, con enorme crecimiento de los gastos". La crítica al Estado de bienestar se funda, en parte, en el hecho que la intervención demasiado potente del Estado quita la responsabilidad a las sociedades menores que podrían actuar por sí mismas. Ya que el Estado quita la libertad de acción a esas sociedades les quita también su responsabilidad porque "sin libertad personal es imposible la responsabilidad moral", como dice Tomás de Aquino (San Francisco Reyes, 1992: 530). El principio de subsidiariedad, según la iglesia católica, puede ser así resumido, lo cual va a tener una influencia mayor en el pensamiento de Jaime Guzmán:

el respeto y la promoción efectiva del primado de la persona y de la familia; la valoración de las asociaciones y de las organizaciones intermedias, en sus opciones fundamentales y en todas aquellas que no pueden ser delegadas o asumidas por otros; el impulso ofrecido a la iniciativa privada, a fin que cada organismo social permanezca, con las propias peculiaridades, al servicio del bien común; la articulación pluralista de la sociedad y la representación de sus fuerzas vitales; la salvaguardia de los derechos de los hombres y de las minorías; la descentralización burocrática y administrativa; el equilibrio entre la esfera pública y privada, con el consecuente reconocimiento de la función social del sector privado; una adecuada responsabilización del ciudadano para ser parte activa de la realidad política y social del país (Pontificio Consejo "Justicia y Paz", 2004, art. 187).

La familia se vuelve el órgano más importante de las sociedades privadas. Su rol en la educación va a ser fundamental y va a tener una prerrogativa primordial en la primera educación de los niños. Como lo afirma Pío XI (1929: 55) en su encíclica Divini Illius Magistri. Sobre la educación cristiana de la juventud, "el primer ambiente natural y necesario de la educación es la familia, destinada, precisamente para esto por el Creador”. Jaime Guzmán va a defender esa visión durante el régimen dictatorial chileno.

\section{Entre catolicismo y neoliberalismo: una mezcla ideológica del principio de subsidiariedad en la educación chilena durante la dictadura de Pinochet (1973-1989)}

Con el golpe de Estado el 11 de septiembre de 1973, un cambio brutal de paradigma educacional, que pasa de una visión de un Estado docente - que "supone un concepto de desarrollo nacional que se articula con una visión, si se quiere, filosófica según la cual el desarrollo del individuo es posible propiciarlo desde el Estado" (Núñez, 2011) y "un Estado [que] no puede ceder a ningún otro poder social la dirección superior de la enseñanza pública" porque se considera que "gobernar es educar, y todo buen sistema de política es un verdadero sistema de educación, así como todo sistema general de educación es un verdadero sistema político" (citado en Riveros, 2002: 2) - a la de la libertad de enseñanza que se funda en "una postura católica y conservadora, que privilegia el derecho de cada familia en la educación, enfatizando lo privado sobre lo público" (Angélica, 2008: 211). La Constitución de 1980, adoptada durante la dictadura y ampliamente redactada por 
Jaime Guzmán, habla por sí misma en cuanto a la prevalencia de la libertad de enseñanza y la importancia de la familia. En su artículo 11 del tercer capítulo se estipula que:

la libertad de enseñanza incluye el derecho de abrir, organizar y mantener establecimientos educacionales. La libertad de enseñanza no tiene otras limitaciones que las impuestas por la moral, las buenas costumbres, el orden público y la seguridad nacional. La enseñanza reconocida oficialmente no podrá orientarse a propagar tendencia político partidista alguna. Los padres tienen el derecho de escoger el establecimiento de enseñanza para sus hijos (Gobierno de Chile, 1980, Cap. III, art. 11).

Se reafirma la libertad de elección de los padres en el artículo 19, 10 del mismo capítulo, ya que "los padres tienen el derecho preferente y el deber de educar a sus hijos" y que "corresponderá al Estado otorgar especial protección al ejercicio de este derecho". La idea de un Estado docente desaparece para dar la prioridad al núcleo familiar, donde se tiene libertad de elección de la educación que se quiere dar a los hijos, una vez que no puede más cumplir su función educativa. El Estado se hace un agente subsidiario de la educación e interviene para garantizar esa posibilidad a los padres. Así, "el Estado es subsidiario de la familia y no la familia subsidiaria del Estado" (CENC, 1975, Sesión 133: 13).

La aplicación del principio de subsidiariedad se justifica por un principio "que algunos piensan que es Dios, otros la naturaleza humana, otros la razón, y que, de todos modos, es superior al Derecho Positivo y sirve de fundamento a sus normas" (Pacheco Gómez, 1988: 431). La privatización de la educación y la preminencia de la subsidiariedad dentro del sistema político de la dictadura se confirma por la propia definición que da la Junta del principio: "ninguna sociedad superior puede arrogarse el campo que respecto a su propio fin específico puedan satisfacer entidades menores, y, en especial, la familia, como tampoco puede invadir ésta lo que es propio e íntimo de cada conciencia humana" (Chile, Gobierno de Chile, 1974: 17). El individuo, como garante del bien común, tiene la posibilidad de asociarse libremente y de cumplir funciones dentro de su asociación privada - participando al bien común por su creación de condiciones que permiten un bien individual para cada uno, como lo dice el inciso cuarto del artículo de la Constitución-, lo que va en contra de un Estado de bienestar y justifica así el principio de subsidiariedad (Núñez, 2011). De manera más concreta, como lo explica María Oliva Angélica (2008: 218):

El principio de subsidiariedad y su corolario, la transformación del rol del Estado en la educación se manifiesta al menos en tres aspectos neurálgicos: el traspaso de la gestión de los establecimientos escolares, desde la dependencia ministerial centralizada a una descentralizada, la municipal; la transferencia de los docentes, de funcionarios públicos a municipales, y el cambio del sistema de financiamiento de la educación pública, desde un modelo basado en la oferta a uno basado en la demanda, estimulando la incorporación masiva de agentes privados (sostenedores) al mercado de la educación.

Por la entrega de la educación al mercado se suma a la subsidiariedad de tradición católica el pensamiento neoliberal. La introducción del neoliberalismo dentro de la educación se caracteriza sobre todo por "la expansión de las escuelas privadas vía financiamiento público, la introducción de mecanismos de competencia [...] entre las escuelas financiadas con recursos públicos, el uso de mecanismos de subvención tipo vouchers; el cobro de aranceles a las familias y la ampliación de las posibilidades de las familias de elegir la escuela de sus hijos" (Angélica, 2008: 220).

El principio de la libertad de enseñanza, con una base católica, se confunde con el principio neoliberal de libertad de mercado del lado de la oferta (Orellana, 
2014: 5). "Y del lado de la 'demanda', el principio de subsidiariedad se legitima mediante el recurso a la teoría del capital humano, que concibe la educación como un bien de capital que, en tanto desigualmente distribuido, introduce asimetrías en los salarios posteriores de los sujetos" (ibid:: 5-6). La confusión entre el principio de subsidiariedad y el pensamiento neoliberal de mercado es total cuando leemos el título del quinto principio de la Declaración de Principios del Gobierno de Chile (1974), "el respeto al principio de subsidiariedad supone la aceptación del derecho de propiedad privada y de la libre iniciativa en el campo económico". La justificación por el carácter natural del mercado y del derecho, que naturalizan a ellos dos la política, permite una justificación casi dogmática del principio de subsidiariedad. Esa naturalización conduce a una supuesta despolitización.

Bajo la aplicación de la subsidiariedad, la junta militar promueve "la despolitización de los cuerpos intermedios, [implantando] una política económica, llamada social de mercado, [subordinando] al Estado al principio de subsidiariedad y [llevando] a cabo hondas transformaciones en la estructura tanto administrativa como social del país" (Cea Egaña, 1988: 34-35). Se implementa una "revolución desde arriba”, según la expresión de Mario Góngora (1981: 260). Esa despolitización se justifica por el hecho que la transmisión de una ideología dentro del sistema escolar sería ir en contra del principio de subsidiariedad porque sería admitir que los partidos políticos y los sindicatos pudieran superar sus propias funciones e invadir el ámbito educacional.

La necesidad de despolitización justifica en parte el carácter democrático de la subsidiariedad. Su consecuencia argumentativa llega a la implementación de un pluralismo escolar. La libertad de enseñanza, garantizada por la Constitución, debe permitir la expresión de un pluralismo dentro del sistema educacional y así ampliar la cobertura. "La libertad de enseñanza comprende el derecho de impartir conocimientos, el de elegir libremente el tipo de enseñanza, el de abrir establecimientos educacionales, organizando su vida interior, administrativa y docente, y la facultad de acreditar el grado de conocimientos adquiridos por los alumnos" (CENC, 1975, Sesión 142: 3) y así se garantiza la expresión de un pluralismo de la oferta educacional, aunque no se puede politizar un establecimiento educativo. La descentralización de la administración permite, en parte, ese pluralismo por la adaptación de los aparatos públicos a cada lugar, además de promover la posibilidad teórica de acercar esos aparatos de la gente, lo cual justifica el carácter democrático de su implementación. Con la subsidiariedad y el fin de un Estado hipertrofiado, "se ha logrado la desconcentración de la administración de los establecimientos educacionales a través de las municipalidades y corporaciones privadas, consiguiendo así una mayor democratización del país" (Martín, 1989: 67).

Sin embargo, la libertad de enseñanza se restringe a algunos actores como lo explica Jaime Guzmán (ibid.: 23), ya que ella "se otorga a los padres de familia o a quienes abran establecimientos educacionales, pero no a los educandos". El principio de pluralismo implica una pluralidad de centro de enseñanza y la libertad de elección de los padres para la educación de sus hijos, lo que significa también la posibilidad de elegir entre una educación estatal o privada. La subsidiariedad necesita una labor del Estado que sea "activa, eficaz, positiva" (San Francisco Reyes, 1992: 547) y que permita así la expresión del pluralismo en contra de un monopolio estatal o de una ausencia total de la autoridad pública. Con ese sistema mixto, sus aportes fiscales directos, indirectos y las diferentes formas de créditos, se justifica la ampliación de la cobertura con, por ejemplo, una "atención escolar en educación prebásica [que] se incrementa en 375,1\% entre 1970 y 1987" (Martín, 1989: 66). El presupuesto estatal se concentra en la educación básica y media, a costa de la educación superior, lo que permite cumplir "con el precepto legal de universalidad de la educación básica, [y] se avanza en la 
democratización del sistema educacional" (ibid:: 67). La cobertura se diversifica también con la creación de múltiples institutos profesionales y centros técnicos (ibid:: 76). Así la descentralización, el pluralismo, la ampliación de la cobertura son ejemplos que confirman el carácter democrático de la subsidiariedad neoliberal y católica teorizada por Jaime Guzmán. Su justificación ideológica y democrática continúa en los gobiernos de la transición.

\section{Una herencia ideológica y estructural: el principio de subsidiariedad en la educación de la transición democrática}

Cuando se promulga la Ley Orgánica Constitucional de Enseñanza (LOCE) en marzo de 1990, durante los últimos días de la dictadura, se deja una herencia del principio de subsidiariedad en el sistema educativo a los gobiernos de la Concertación que van a implementar un proceso de transición hacia la democracia. La LOCE regula ciertos criterios para la enseñanza básica y media sobre los requisitos de ingreso y egreso, de reconocimiento oficial de los establecimientos de cada nivel, y las normas objetivas que permiten al Estado hacer cumplir esos requisitos. Esa última disposición "permite concluir que se refiere a que no debió hacerse diferencias entre la enseñanza estatal y la enseñanza privada y el Estado tiene competencia para vigilar ambas y, a la vez, para exigir que se cumplan los requisitos mínimos establecidos" (San Francisco Reyes, 1992: 546). La igualación entre la educación pública y privada muestra que el Estado toma plenamente un rol de agente subsidiario que delega una parte de su prerrogativa al ámbito privado.

Con la LOCE se consolida el régimen neoliberal generando así una profundización del principio de subsidiaridad. La prevalencia de la educación privada se subraya en el título preliminar "Normas Generales y Conceptos" de la LOCE al reiterar el artículo 3 de la Constitución que proclama una administración estatal descentralizada y desconcentrada:
"El Estado tiene, asimismo, el deber de resguardar especialmente la libertad de enseñanza. Es deber del Estado financiar un sistema gratuito destinado a asegurar el acceso de la población a la enseñanza básica” (MINEDUC 1990, Ley 18 962: 612). Como lo explica Angélica (2008: 222), "esto permite poner en práctica el principio de subsidiariedad mediante la municipalización y el cambio en el sistema de financiamiento de subsidio por alumnos o subsidio a la demanda". La libertad de enseñanza es, una vez más, declarada por el principio rector del sistema educacional chileno. No hay más atención preferente del Estado hacia la educación sino la entrega de sus prerrogativas educacionales al mercado en el cual el Estado se hace un competidor como otro. "Así, el proceso de creación de mercados educacionales se concreta en cuatro tipos de establecimientos educacionales: establecimientos municipales, colegios particulares subvencionados, colegios particulares pagados y corporaciones educacionales dependientes de organizaciones empresariales" (ibid.).

Con el artículo 21 de la LOGE se proclama una radicalización del principio de subsidiariedad en su versión neoliberal:

El Ministerio de Educación reconocerá oficialmente a los establecimientos educacionales que impartan enseñanzas en los niveles básico y medio, cuando así lo soliciten y cumplan con los siguientes requisitos: tener un sostenedor, que podrá ser una persona natural o jurídica, que será responsable del funcionamiento del establecimiento educacional. Dicho sostenedor o representante legal, en su caso, deberá a lo menos contar con licencia de educación media (MINEDUC, 1990, Ley 18 962: 619).

Por esa subsidiariedad neoliberal, la posibilidad de competir en el mercado educacional es restringida por condiciones tan mínimas que casi cualquier actor, con suficientes fondos, puede hacerse emprendedor en ese nuevo mercado. La posibilidad de crear 
establecimientos educacionales con fines de lucro genera un negocio fructífero. "Las universidades, por ejemplo, incorporan a la banca al negocio con el crédito bancario fiscal o privado, crédito que se entrega a los estudiantes que no disponen de los medios para financiar su educación superior" (Angélica, 2008: 223). Las consecuencias de la LOCE y su radicalización de la subsidiariedad se quedan tal cual durante los años de transición.

En el proyecto de Ley de Educación Superior del gobierno de Patricio Aylwin (1990-1994), que no tendrá éxito en el trámite legislativo, el principio de subsidiariedad es así enunciado:

Los estudiantes deben concurrir a financiar en la medida de sus posibilidades económicas el costo de la enseñanza que reciben la cual les permitirá más adelante obtener ingresos provenientes del ejercicio de una profesión o actividad certificada por el respectivo título técnico. Si no se procediera de esta forma se violaría el principio de equidad, sobre todo si se considera que en Chile sólo 18 de cada 100 jóvenes del respectivo grupo de edad ingresan a algún establecimiento de educación superior, de donde egresan premunidos de los conocimientos y certificados educacionales que los colocan en posiciones de relativo privilegio respecto a la gran mayoría de los chilenos, permitiéndoles obtener ingresos adicionales que provienen, precisamente, de su formación superior (citado por Orellana, 2014: 10).

Haciendo de los estudiantes competidores dentro del mercado educacional, su privilegio de entrar en la universidad tiene que ser "equitativo" y, por ende, necesita un arancel. Si al estudiante le falta dinero para acceder al privilegio de la educación superior se implementa un subsidio a la demanda, pero no a las instituciones:

que los préstamos estudiantiles que se ofrezcan puedan ser obtenidos por cualquier estudiante que reúna las condiciones necesarias, independiente de la institución reconocida oficialmente en que curse estudios [...], que el aprovechamiento de las becas de arancel diferenciado con recursos fiscales quede reservado exclusivamente para aquellos establecimientos que se hayan incorporado voluntariamente al procedimiento de acreditación propuesto en la nueva legislación (citado por Orellana, 2014: 10).

Por el lado de la "oferta", se señala que:

debe asegurarse que una proporción significativa de las asignaciones fiscales a la educación superior sea canalizada mediante mecanismos que incentiven a las instituciones receptoras a incrementar la calidad, la eficiencia y la relevancia de las actividades que acometen [...] La asignación de los recursos fiscales debe ser regulada de modo tal que las diversas instituciones, que parten de una base desigual de capacidades, puedan efectivamente desarrollarse de acuerdo a sus necesidades [... ello] refuerza la efectiva autonomía de las instituciones y crea oportunidades diferenciadas de acceso a esos recursos. En general, cabe esperar de tal sistema que las diversas instituciones, aprovechando su libertad de iniciativa, podrán reforzar sus propias definiciones de misión y su identidad (citado por Orellana, 2014: 10-11).

El rol del Estado es de regulador del mercado educacional. En esa doble postura, a la vez de regulador y de competidor, el principio de subsidiariedad se consagra, en el contexto de la transición, como un signo de modernización del país. Así se puede leer que "un objetivo primordial de la política de desarrollo de la educación superior durante la presente década debe ser la consolidación de la diversificada base institucional existente" (citado por Orellana, 2014: 11). Con el documento de 1997 "Marco de política en educación superior", se destaca la doble postura del Estado: 
El marco de política de 1997, por el contrario, apuesta por ampliar la cobertura de la educación superior mediante la expansión de la matrícula, para lo cual se requiere que los estudiantes en el nuevo sector privado tengan acceso a alguna forma de ayudas estudiantiles, que hasta entonces habían estado principalmente orientadas a los estudiantes de las universidades del Consejo de Rectores. Esta nueva orientación se hace cargo del sostenido crecimiento que el nuevo sector privado había venido experimentando desde 1990. El logro de este objetivo implicó ampliar el rol de la competencia en el marco de política, que en adelante sería cualitativa y cuantitativa a la vez (Salazar y Leihy, 2013: 23).

Esos ejemplos testiguan de una continuidad ideológica del principio de subsidiariedad de la dictadura a los gobiernos de la Concertación. Ahora, nos queda cuestionar la aplicación de principio de subsidiariedad neoliberal dentro del sistema educacional.

\section{La alternativa democrática de la subsidiariedad en la educación La educación, expresión primaria de lo político}

El principio de subsidiariedad tal cual lo estudiamos hasta ahora define el bien común como condiciones generadas por agentes privados que les permiten alcanzar sus propios fines específicos. Esa definición del bien común se enmarca en un pensamiento individualista de la política. La sociedad está al servicio del individuo según el pensamiento de Jaime Guzmán, de lo cual se establece la definición canónica de la subsidiariedad en el sistema chileno. Por su tendencia a socializar, el ser humano forma sociedades intermedias que no pueden ser restringidas por la acción del poder público, salvo si va en contra del bien común.

Sin embargo, esa definición individualista del bien común es problemática en varios sentidos. Primero, define un bien común según una suma de bienes individuales. Segundo, y como consecuencia de lo primero, no se puede hacer política bajo la única satisfacción individual o específica de un grupo particular. Esa consecuencia es tomada por Guzmán como lógica ya que, según él, el hecho de garantizar la autonomía de las sociedades intermedias, por la aplicación de la subsidiariedad, debe permitir una despolitización de la sociedad. Los sindicatos o grupos políticos, como grupos intermedios, no pueden interferir con otros grupos que siguen sus propios fines. La política se vuelve una actividad que busca ciertos fines específicos que deben conducir al bien de algunos. El Estado es el órgano supremo que asume las funciones que no pueden asumir las sociedades intermedias. Su acción subsidiaria permite así una sociedad libre, según Jaime Guzmán (Núñez, 2011).

La definición del bien común, según una tradición individualista y utilitarista que calcula la felicidad general por la suma de la felicidad de cada uno, conduce a la tradicional objeción que se hace al utilitarismo y que demuestra que los intereses de uno pueden estar en conflicto con los de otro. Por esa razón, no se puede definir el bien común según las condiciones que llevan a los fines específicos de cada uno porque esas condiciones, que llevan felicidad para uno, pueden contrariar a otro y así ir en contra del bien común. Al contrario de la teorización neoliberal, que ve en el mercado un principio regulador en el cual el Estado tiene que intervenir lo menos posible, la definición individualista del bien común conduce a una confrontación incesante de intereses personales entre sí.

Por la aparición de esos numerosos conflictos que la competencia de intereses genera, la política reaparece. Primero, reaparece en la necesidad de una resolución de los conflictos que se enmarca en la contestación de una cierta hegemonía. Segundo, y los más importante, hay conflicto no sólo entre intereses competidores sino entre actores que se disputan el "reparto de lo sensible", según la expresión de 
Jacques Rancière (2006 [1998]: 72). "La esencia de la política es el disenso. El disenso no es la confrontación de intereses u opiniones. Es la manifestación de una separación de lo sensible consigo mismo. La manifestación política deja ver lo que no tenía razones de ser visto, aloja un mundo en otro" (ibid.: 73). La despolitización que propone Jaime Guzmán bajo la objetividad de su teorización política del Estado y del ser humano se inserta típicamente en lo que Rancière llama el consenso y la policía:

La esencia del consenso es la anulación del disenso como distancia de lo sensible consigo mismo, la anulación de los sujetos excedentarios, la reducción del pueblo a la suma de las partes del cuerpo social y de la comunidad política a relaciones de intereses y de aspiraciones de esas diferentes partes. El consenso es la reducción de la política a la policía. Es el fin de la política, es decir, no el cumplimiento de sus fines sino simplemente el retorno del estado normal de cosas que es el de su no-existencia (Rancière, 2006 [1998]: 78).

La despolitización, según Guzmán y como consecuencia directa de la subsidiariedad, niega la constante aparición de sujetos políticos que se oponen a un reparto consensual de lo sensible. La invisibilidad se vuelve visible. El pingüinazo de 2006 fue la generación de un nuevo grupo político que era considerado por la dictadura como consumidores dentro del mercado educacional, es decir, seres normalizados que, por su libertad de elegir, pueden satisfacer sus fines personales. Lo que falta a la teoría católicaneoliberal de Jaime Guzmán es la imposibilidad de pensar lo colectivo más allá de la individualidad. La sociedad no es quimérica. Hay una transcendencia inmanente de lo social. Los individuos en grupo no son sólo una suma de individualidades, sino que generan una potencia particular que lo supera, lo transciende, pero que tiene su base en los individuos mismos, es decir, es inmanente. Lo que podemos llamar, con Spinoza, la potencia de la multitud. Esa superación no encuentra un origen particular. Como lo escribe Emile Durkheim, tomando por ejemplo la institución de la religión:

ciertamente si por origen, se entiende un primer comienzo absoluto, la cuestión no tiene nada de científica y debe descartarse resueltamente. No hay un instante radical en que la religión haya comenzado a existir y no se trata de encontrar un atajo que nos permita transportamos allí con el pensamiento. Como toda institución humana, la religión no comienza en ninguna parte (Durkheim, 1912: 12).

La transcendencia de lo social, que el pensamiento de Guzmán no puede pensar, se nota en la experiencia de un ser humano que realiza un discurso al frente de un grupo de gente. El hombre que habla a la multitud "siente en él como una plétora anormal de fuerzas que lo desbordan y tienden a expandirse fuera de él; tiene hasta la impresión de que está dominado por una potencia moral que lo supera y de la cual no es más que el intérprete" (Durkheim, 1912: 302). Por la demostración de la transcendencia inmanente de lo social se confirma la imposibilidad de pensar el bien común según un pensamiento individualista. Hay conflictos políticos que se generan y que son guiados por diferentes concepciones del bien común. El Estado despolitizado y actor de la subsidiariedad es uno de ellos.

La educación es generadora de una cierta visión de lo social y, por ende, de una cierta visión del bien común. En su propia transcendencia inmanente, y como lugar de producción de saber, es decir de un cierto reparto de lo sensible, pero también por la posible inestabilidad que genera el proceso sensible de educación y enseñanza, el sistema educacional no puede ser asumido por particulares que contemplan sólo fines particulares. La educación se sitúa fuera del proceso de producción. El estudiante no es un trabajador y no estudia para producir sino para 
aprender. Del jefe al trabajador se constituye una relación de dominación ya que ese último tiene que entregar su única fuerza de trabajo en contra de un salario. Mientras que la relación entre el maestro y el estudiante es de voluntad a voluntad y no de dominación por la superioridad del sabio. El método del profesor Joseph Jacotot, protagonista de El Maestro Ignorante de Rancière, muestra que "se puede enseñar lo que ignoramos si emancipamos al estudiante, es decir si lo obligamos a utilizar su propia inteligencia" (Rancière, 1987: 11).

La reivindicación de los estudiantes chilenos que afirman que la educación es un derecho y no un privilegio, entiende la necesidad de la educación en la formación de lo social y de la comunidad política que conlleva. No es prerrogativa de particulares ser los protagonistas del sistema educacional, sino del poder público que, en su carácter democrático, debe proclamar una igualdad radical entre sus actores, es decir, que rechaza la capacidad en lo político, y no una igualdad de libertad de elección. Hacer de la educación un asunto privado es negar la importancia de la formación política necesaria a cada ser humano para desempeñar plenamente su existencia dentro de la comunidad en la cual vive. Por su privatización, la educación se vuelve un bien específico al cual sólo algunos pueden acceder, además de dañar la calidad de un sistema que debería ser abierto a todos, ya que su constitución es fundamental a la participación política de las nuevas generaciones, las cuales no podrán vivir juntas sin esa participación.

Basado en la evidencia y la literatura analizadas, mis conclusiones acerca del aporte de la expansión de la educación privada financiada por el Estado en términos de resultados de aprendizaje - son las siguientes. Primero, las escuelas privadas subvencionadas - en promedio - no son más efectivas en producir resultados de aprendizaje que las escuelas públicas; más aún, si alguna diferencia existe, ésta parece favorecer a las escuelas públicas (dado que sabemos que las estimaciones han tendido a sobrevalorar el efecto de las escuelas privadas). Segundo, de existir alguna diferencia en la efectividad entre escuelas públicas y privadas (en cualquiera de los dos sentidos), es casi seguro que ésta es de magnitudes muy pequeñas, sustantivamente irrelevantes. Tercero, en el mejor de los casos, la fuerte expansión de la educación privada subvencionada no ha provocado un mejoramiento apreciable de la calidad del sistema escolar chileno como un todo. Cuarto, existe evidencia que sugiere que la expansión de las escuelas privadas ha aumentado la segmentación y por esa vía la inequidad de la educación chilena (Bellei, 2007: 308-309).

La prueba sociológica del mal funcionamiento del sistema educacional regido por reglas de mercado muestra la imposibilidad de considerar la educación como un bien privado que puede ser sujeto a la competencia. La subsidiariedad, que entrega las formaciones educacionales a los agentes privados para que ellos puedan realizar las funciones que su empresa tiene que cumplir, es una forma particular de la subsidiariedad. Ahora tenemos que estudiar si otra forma de subsidiariedad podría aplicarse al ámbito educacional.

\section{Una propuesta horizontal de la subsidiariedad}

La subsidiariedad, según Jaime Guzmán, toma una forma jerárquica. Su inspiración católica y su constante llamada a un orden natural, que sea religioso o económico, da una superioridad al individuo como ser esencial que debe tener el Estado a su servicio. Frente a esa visión, se puede desarrollar un enfoque federativo de la subsidiariedad. Según el filósofo calvinista Johannes Althusius, del siglo XVI, existen diferentes esferas de soberanía y no sólo la del individuo o de la potencia divina. Un principio federativo se construye entre las diferentes asociaciones 
que forman entre ellas una sociedad. "La autoridad política, argumenta, 'emerge no desde un acuerdo entre individuos, sino entre asociaciones', las cuales son, en esencia y en la práctica, 'necesarias para satisfacer - subsidiar - las necesidades individuales' " (Ortúzar, 2015: 6).

$\mathrm{Al}$ contrario de una visión individualista que entiende al sujeto como un ser que se asocia para satisfacer sus intereses dentro un grupo que cumple ciertas funciones, Althusius postula la necesaria asociación de los seres humanos en asociaciones distintas que se unen para formar asociaciones más grandes que podemos llamar naciones o Estados. Ya que esa asociación superior no puede cumplir todas las funciones que necesita su población, ella tiene que funcionar gracias a la subsidiariedad. El bien común considera el bien de cada asociación, pero no puede ser implementado por ellas, sino sería un bien particular. Por ello la autoridad, que reúne la de todas, tiene que determinar cuál es bien que puede satisfacer a todas, es decir su bien común. "La política es el arte de establecer, de cultivar y conservar entre los hombres la vida social que tiene que unirlos. Es lo que llamamos la simbiótica" (citado por Lordon, 2015: 203, traducción propia).

Las autoridades se dispersan entre las diferentes asociaciones que deben reunirse para coordinarse. Sin embargo, la potencia de su reunión es nula si ellas se separan. Es decir que su soberanía máxima es contingente del buen desarrollo de su reunión. El juego de las interacciones entre los seres humanos crea la vida social. "Los demás no son simples medios para ayudar al individuo a paliar sus insuficiencias, sino la condición de posibilidad de la emergencia de las capacidades individuales y del espacio social" (citado por Lordon, 2015: 205, traducción propia). Así, el poder concedido a uno es siempre menor al poder que uno concede. Las asociaciones intermedias fundan el poder general. Esa forma de una soberanía subsidiaria contrasta con la subsidiariedad de Jaime Guzmán que da la predominancia al individuo soberano cuyo bien individual debería ser la base de lo común. En vez de pensar entidades esencialistas, como el individuo o la familia, "el énfasis en la aplicación del principio [de subsidiariedad] se vuelve más territorial. [...] El énfasis está en las políticas supranacionales y en organizaciones territoriales como el Estado, la región, el municipio y la comunidad local" (Ortúzar, 2015: 10).

En el ámbito educacional, la teorización del principio de subsidiariedad de Althusius permite pensar un modelo ajeno del sistema de la dictadura. Por su generación de lo social, el principio de subsidiariedad de Althusius dentro del sistema educacional debería posibilitar la participación de todos los grupos constituidos dentro de los establecimientos de educación. Podemos encontrar una aplicación histórica de ese principio bajo el concepto de cogobierno desde el planteamiento de ese principio por los estudiantes de Córdoba, hasta su defensa por los estudiantes chilenos en los años sesenta.

Los estudiantes de Córdoba plantearon que correspondía a los estudiantes, junto a los académicos, la generación de autoridades. Esto sirvió de fundamento para la tesis del cogobierno, que será recogida por los estudiantes chilenos en los años 60 . Los reformistas de Córdoba manifestaron que "el demo universitario, la soberanía, el derecho a darse el gobierno propio radica principalmente en los estudiantes". Como lo expresara uno de los actores y más tarde, cronista del movimiento de Córdoba, "la Universidad es una Republica de Estudiantes. [...] Son estudiantes todos los copartícipes en la Comunidad de estudios. Sus miembros van recibiendo graduación sucesiva: alumnos, licenciados, profesionales, doctores, maestros". De acuerdo con este concepto de la soberanía universitaria, correspondía a los estudiantes un tercio de los votos; los otros dos tercios se repartían entre los diplomados y los profesores, recibiendo cada uno un tercio $(\mathrm{Hu}-$ neeus, 1988: 10). 
La idea radical de un común reparto de la autoridad se asimila a la subsidiariedad según Althusius. Cada asociación es soberana y su asociación con otras, para formar, en ese caso, una universidad, genera una potencia política nueva que, sin embargo, no puede superar el poder que le otorgan las asociaciones que permiten esa potencia. La reivindicación actual de una gestión triestamental por los estudiantes chilenos es una herencia directa del Manifesto de Córdoba. Los estudiantes, los académicos y los funcionarios son la base de la institución política de un establecimiento escolar cuya soberanía y autonomía no podrían sostenerse sin la constitución social que lleva cada una de sus bases.

El sistema educacional nacional tendría que constituirse por un órgano federativo que reúne las diferentes asociaciones educativas. Por ende, existiría un deber participativo a lo común de las diferentes asociaciones. Todas las formas de asociaciones educativas tendrían que participar en ese órgano llevando alternativas o comprobando métodos educacionales. El asunto educacional sería así una parte mayor de la comunidad política en la cual evolucionaría. La subsidiariedad sería un remedio en contra de una tentación autoritaria de la autoridad central, pero, sobre todo, el reconocimiento de la potencia de los que conceden el poder en vez de los que lo detienen. La subsidiariedad según Althusius es grande por su respeto y reconocimiento de la potencia de los cuerpos sociales y de su proceso de constitución. Por la subsidiariedad horizontal, que niega a la autoridad, que reúne las asociaciones intermedias, una superioridad jerárquica, la educación toma su pleno sentido político. Así, se puede desempeñar la autonomía y la responsabilidad de cada asociación política coordinándose con las otras asociaciones que cooperan en la misma función que ella, al revés del ideal competitivo de Jaime Guzmán.

\section{Conclusión}

Bajo una mezcla teórica entre la tradición católica y neoliberal, el pensamiento de Jaime Guzmán influyó considerablemente en el sistema educacional chileno. Según él, la aplicación del principio de subsidiariedad debe respetar la soberanía absoluta del individuo y favorecer la realización del bien común cuyo sustento son las condiciones establecidas por la iniciativa privada que lleva a los individuos la felicidad que ellos buscan. Con la entrega del sistema educativo a las leyes del mercado, éste se vuelve en bien de consumo por el cual el Estado tiene también que competir para atraer su propia demanda. En contra de una visión individualista de la sociedad, la transcendencia inmanente de lo social permite entender la superación de sí mismo que los propios individuos pueden generar. La educación se constituye como espacio de construcción primaria de lo social en el que los estudiantes son actores políticos del renuevo. La subsidiariedad horizontal, teorizada por Althusius, permite pensar la coordinación y la politización de los espacios educacionales que poseen ese lugar tan particular dentro de una comunidad política. La federación educativa podría ser la antesala de la democracia como espacio de producción primaria de lo social, y una tentativa de formación de nuevos seres políticos. 


\section{Referencias}

Aguilera, J. C. y A. S. Rodríguez (s.f.), "Principios de subsidiariedad y equidad en la gestión de las organizaciones educativas", en Sección del Congreso: Políticas de Equidad, Navarra, Universidad de Navarra, recuperado de <http://www.unav.es/educacion/ sociedu 1/textos /Comunicaciones/ponencia_Bs._. Aires.doc $>$ [Consulta: junio de 2016]

Angélica, M. O. (2008), "Política educativa y profundización de la desigualdad en Chile", Estudios Pedagógicos XXXIV, núm. 2, pp. 207-226.

Aroney, N. (2014), "Subsidiarity in the writings of Aristotle and Aquinas", en Michelle Evans y Augusto Zimmermann, Global Perspectives on subsidiarity, Nueva York, Springer.

Bellei, C. (2007), "Expansión de la educación privada y mejoramiento de la educación en Chile. Evaluación a partir de la evidencia”, Pensamiento Educativo, vol. 40, núm. 1, pp. 285-311.

Cea Egaña, J. L. (1988), Tratado de la Constitución de 1980, Santiago, Editorial jurídica de Chile.

Comisión de Estudio de la Nueva Constitución (CENC) (1975), Actas oficiales de la CENC, Sesión 133, 26-6-75, Sesión 141, 24-7-75, y Sesión 142, 29-7-75, Buenos Aires, CENC.

Durkheim, E. (1912), Las formas elementales de la vida religiosa, México, Colofón, recuperado de <www. arnaldomartinez.net/sociologia/durkheim_Las_ formas.pdf> [Consulta: julio de 2016].

Gobierno de Chile (1980), Constitución Política de la República de Chile (Última modificación, 16 de noviembre 2015 Ley 20870), <https://www.leychile.cl/ $\mathrm{N} ? \mathrm{i}=242302 \& \mathrm{f}=2015-11-16 \& \mathrm{p}>$ [Consulta: julio de 2016].

Gobierno de Chile (1974), Declaración de Principios del Gobierno de Chile, Santiago, Editorial Gabriela Mistral.

Góngora, M. (1981), Ensayo histórico sobre la noción de Estado en Chile en los siglos XIX y XX, Santiago, Editores La Ciudad.

Guzmán, J. (1993), Escritos personales, Santiago, Zig-Zag.
Huneeus, G. (1988), La reforma universitaria. Veinte años después, Santiago, Corporación de Promoción Universitaria.

Juan Pablo II (1991), Centesimus Annus, < http://w2.vatican. va/content/john-paul-ii/es/encyclicals/documents/ hf_jp-ii_enc_01051991_centesimus-annus.html> [Consulta: julio de 2016].

León XIII (1891), Rerum Novarum. Sobre la condición de los obreros, <http://w2.vatican.va/content/leo-xiii/es/ encyclicals/documents/hf_l-xiii_enc_15051891_ rerum-novarum.html> [Consulta: julio de 2016].

Lordon, F. (2015), Imperium. Structures et affects des corps politiques, París, La Fabrique Editions.

Martín, R. S. (1989), "El proceso educacional del país", en Política, diciembre, Santiago, Instituto de Ciencia Política, Universidad de Chile.

Núñez, S. (2011), "Educación superior en Chile y principio de subsidiariedad: introducción a su fundamentación filosófica", Tesis para optar al grado de Licenciado en Filosofía, Santiago, Universidad de Chile, Facultad de Filosofía y Humanidades, <http://repositorio.uchile. cl/tesis/uchile/2011/fi-nunez_s/html/index-frames. html> [Consulta: junio de 2016].

Orellana, V. C. (2014), La subsidiariedad en la política pública de educación superior en Chile (1980-2013), Santiago, Fundación Nodo XXI.

Ortúzar, P. M. (2015), El principio de subsidiariedad, 4 claves para un debate, Instituto de Estudios de la Sociedad (IES Chile), <http://www.ieschile.cl/claves/subsi.pdf> [Consulta: junio de 2016].

Pacheco Gómez, M. (1988), Teoría del derecho, Santiago, Editorial Jurídica.

Pío XI (1929), Divini Illius Magistri. Sobre la educacion cristiana de la juventud, <http://w2.vatican.va/content/pius-xi/ es/encyclicals/documents/hf_p-xi_enc_31121929_ divini-illius-magistri.html> [Consulta: 7/07/2016].

Pío XI (1931), Quadragesimo Anno. Sobre la restauración del orden social, <http://w2.vatican.va/content/pius-xi/ es/encyclicals/documents/hf_p-xi_enc_19310515_ quadragesimo-anno.html> [Consulta: junio de 2016]. 
Pontificio Consejo "Justicia y Paz" (2004), Compendio de Doctrina Social de la Iglesia Católica, <www. caritasregiondemurcia.org/wp.../DOCTRINASOCIAL-DE-LA-IGLESIA.pdf> [Consulta: junio de $2016]$.

Rancière, J. (2006 [1998]), "Diez tesis sobre política”, en Política, policía, democracia, Santiago, LOM Ediciones.

Rancière, J. (1987), Le maître ignorant, cinq leçons sur l'émancipation intellectuelle, París, Librairie Arthème Fayard.

Riveros, L. (2002), "Tres momentos históricos de la Universidad de Chile: Andrés Bello, Valentín Letelier,
Juvenal Hernández", Discurso pronunciado en el marco del $160^{\circ}$ aniversario de la Universidad de Chile, 20 de noviembre, Salón de Honor, Santiago de Chile, Universidad de Chile (9 pp.).

Salazar, J. M. y P. S. Leihy (2013), "El Manual Invisible: tres décadas de políticas de educación superior en Chile (1980-2010)", Archivos Analíticos de Políticas Educativas, vol. 21, pp. 1-35.

San Francisco Reyes, A. (1992), “Jaime Guzmán y el principio de subsidiariedad educacional en la Constitución de 1980", Revista Chilena de Derecho, vol. 19, núm. 3, pp. 527-548. 